\title{
Vertical structure, turbulent mixing and fluxes during Lagrangian observations of an upwelling filament system off Northwest Iberia
}

\author{
E.D. Barton ${ }^{\mathrm{a}, *}$, M.E. Inall ${ }^{\mathrm{b}}$, T.J. Sherwin ${ }^{\mathrm{c}}$, R. Torres ${ }^{\mathrm{a}}$ \\ a School of Ocean Sciences, University of Wales, Bangor, UK \\ b Scottish Association for Marine Science, Dunstaffnage Marine Laboratory, Oban, UK \\ ${ }^{\mathrm{c}}$ Centre for Applied Oceanography, University of Wales, Bangor, UK
}

\begin{abstract}
In August 1998, a recurrent filament located near $42^{\circ} \mathrm{N}$ off Galicia was sampled as part of the OMEX-II project. Lagrangian and other observations were made on the shelf where the filament arose and offshore in the filament itself under upwelling favourable but fluctuating winds. The shelf drift experiment monitored a change from southward to weak northward net flow as the winds decreased to zero. Shipborne ADCP measurements showed that the shelf was supplying decreasing volumes of water to the filament as the wind speeds decreased. At the shelf edge the internal tide was larger than can be explained by local forcing and there were many unusually large high frequency internal waves with a quasi-sinusoidal form. Turbulence observations revealed enhanced dissipation rates and vertical eddy diffusion coefficients within the shelf thermocline (of order $1 \mathrm{~cm}^{2} \mathrm{~s}^{-1}$ ), which appeared to be caused by the breaking of internal wave. A second Lagrangian experiment was executed in the filament some $120 \mathrm{~km}$ offshore, which again coincided with a period of wind relaxation. Cross-sections revealed a double cold core and that the offshore flow was limited to a thin surface layer. Substantial onshore flow occurred below $50 \mathrm{~m}$ in the centre of the filament, while the strongest and deepest offshore flow coincided with its northern boundary. Turbulent kinetic energy dissipation rate measurements showed very weak mixing below $15 \mathrm{~m}$ in the filament core, but enhanced mixing at its boundaries. Four mixed layer drifters released in the filament initially indicated convergence at its southern boundary, marked by strong temperature and salinity contrasts. After the wind became more favourable for upwelling, the drifters accelerated. One drifter traced the full extent of the filament, while the other three escaped from it and began to circulate cyclonically over 28 days in a $100 \mathrm{~km}$ diameter loop back towards their release point. Although strong mesoscale activity linked the shelf and ocean regimes, offshore transport in the filament was weak at the time of the experiment and vertical and horizontal re-circulations on a variety of time scales were important. There was sufficient vertical mixing in the thermocline to cause it to thicken and draw some heat into the lower layers during the summer months on the shelf. The amount of heat involved was too little to have a significant impact on the development of a filament over a typical lifetime of a week. (C) 2001 Elsevier Science Ltd. All rights reserved.
\end{abstract}

\footnotetext{
* Corresponding author.

E-mail address: e.d.barton@sos.bangor.ac.uk (E.D. Barton).
} 


\section{Contents}

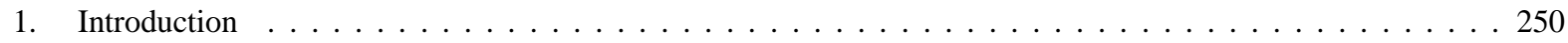

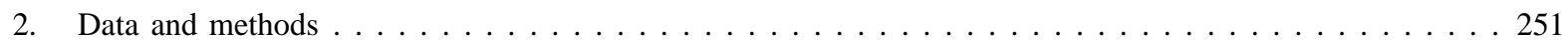

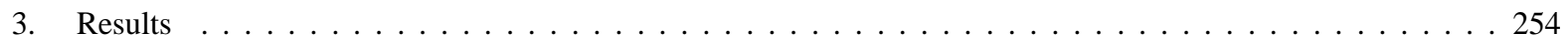

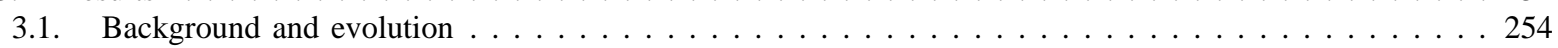

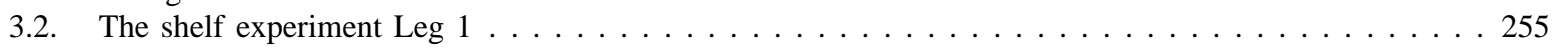

3.2.1. Water column structure and fluxes during the drift $\ldots \ldots \ldots \ldots \ldots \ldots \ldots \ldots \ldots \ldots$

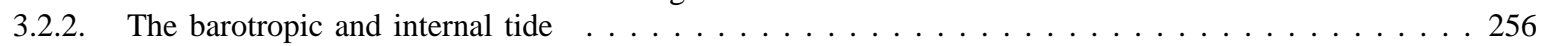

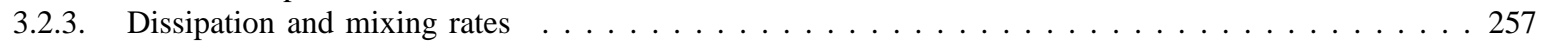

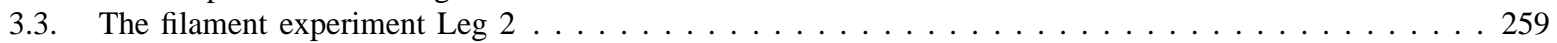

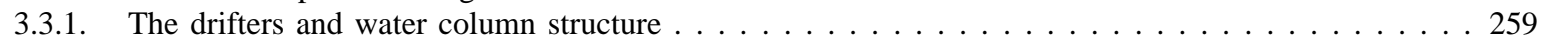

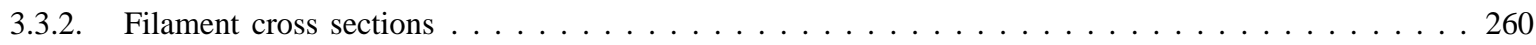

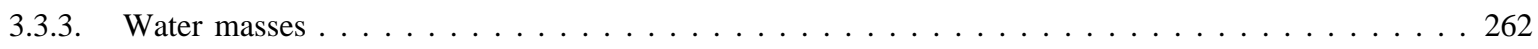

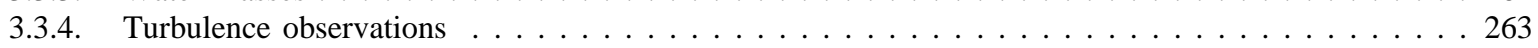

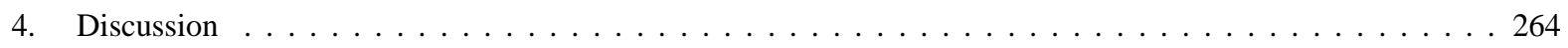

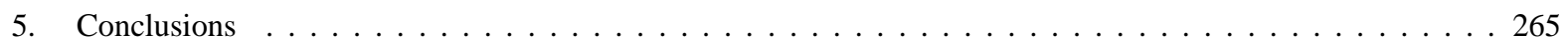

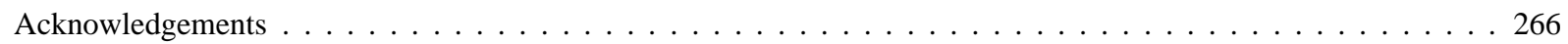

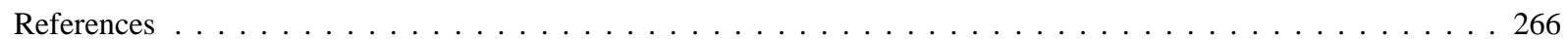

\section{Introduction}

Remote sensing observations of the western Iberian shelf in summer indicate that two important physical processes are the formation of upwelling filaments and internal waves. An understanding of the relative importance of these two phenomena in the vertical and horizontal exchange of matter near the shelf edge is a necessary part of quantifying exchanges at the ocean margin. The Iberian region, like other coastal upwelling regions, is characterised by the presence of filaments of cool upwelled water, which collectively form a coastal transition zone between shelf and open ocean waters (Brink \& Cowles, 1991). These filaments are associated with narrow baroclinic jets that form over the continental shelf and flow offshore advecting cold, upwelled water into the open ocean. They are easily identified by their temperature signatures in satellite images of Sea Surface Temperature (SST) (Flament, Armi, \& Washburn, 1985). Many projects have focussed on filaments in recent years in Eastern Boundary Systems (i.e. California, South Africa, Canaries, Chile) because it is likely that they enhance exchange between the productive shelf and the oligotrophic oceanic waters offshore.

Following the onset of seasonal upwelling off Iberia in either May or June, filaments begin to develop in July or August. By September they have grown to lengths of $200 \mathrm{~km}$ (Haynes, Barton, \& Pilling, 1993), but quickly disappear with the cessation of upwelling favourable winds in October. The filaments have been observed to develop over many years in similar locations, which suggests that they are topographically controlled, although they show high variability on time scales of the order of a week. A recent modelling 
study (Roed \& Shi, 1999) suggested that topography generated local differences in the frontal configuration, which then triggered instabilities and downstream meandering that anchor the filaments close to, and at intervals, downstream of the cause.

Internal tides develop through the interactions between the barotropic tide and stratification, where there is steep topography, such as close to a shelf break. If the shelf slope is super-critical then there will be an almost equal partition of internal tidal energy flux onto the shelf and into the ocean (e.g. Craig, 1987). On the shelf one can expect to see a first mode tidal displacement of the thermocline which, if sufficiently large, will decompose into a band of non-linear internal waves (NIWs) that propagate towards the coast (e.g. Gerkema \& Zimmerman, 1995). In the ocean an internal tide will tend to propagate downwards along characteristic features that may eventually return energy to the surface far offshore.

Anomalously large NIWs have been observed along the Portuguese Shelf at $41^{\circ} \mathrm{N}$ (Jeans, personal communication). They propagate towards the coast at about $0.57 \mathrm{~m} \mathrm{~s}^{-1}$, with vertical downward displacements of the thermocline of up to $45 \mathrm{~m}$ and are accompanied by surges of current in the surface layer of up to $0.45 \mathrm{~m} \mathrm{~s}^{-1}$. Vertical eddy diffusion, averaged over tidal cycle, was estimated from thermistor chain observations to be about $22 \mathrm{~cm}^{2} \mathrm{~s}^{-1}$ in the thermocline. Significant erosion of the thermocline occurred on the shelf during a period of upwelling favourable winds. The large size of the NIWs at $41^{\circ} \mathrm{N}$ was surprising, given the width of the shelf, and merited a further investigation of internal wave mixing off Galicia.

Turbulent kinetic energy dissipation, $\varepsilon$, is a measure of small-scale mixing (of order $1 \mathrm{~cm}$ ). It can be measured directly in the sea and is normally converted to a vertical diffusion coefficient, $K_{Z}$, using (as here) $K_{Z}=0.2 \varepsilon / \rho N^{2}$ (Osborn, 1980) where $N$ is the local buoyancy frequency; and $\rho$ is density (assuming that $\varepsilon$ is in $\mathrm{W} \mathrm{m}^{-3}$ ). Dissipation measurements in internal waves at a shelf edge have been made on the Scotian Shelf, where the vertical eddy diffusivity ranged between 0.1 and $1 \mathrm{~cm}^{2} \mathrm{~s}^{-1}$ (Sandstrom \& Oakey, 1995), and on the Malin Shelf where the values were between 2 and $13 \mathrm{~cm}^{2} \mathrm{~s}^{-1}$ (Inall, Rippeth, \& Sherwin, 2000). Only few observations of turbulent dissipation in filament structures have been made. In a $100 \mathrm{~km}$ wide eddy-like feature off Oregon, Moum, Caldwell, and Stabeno (1988) found very low dissipation levels $\left(<10^{-5} \mathrm{~W} \mathrm{~m}^{-3}\right)$ in the core but higher values in regions of high shear along the edge of the structure and in an intrusion into its core. Generally low dissipation levels have been observed below the surface layer in some upwelling filaments off California (Dewey, Crawford, Gargett, \& Oakey, 1987), apart from in the core of a narrow (10 km wide) filament, where locally enhanced values of order $10^{-3} \mathrm{~W} \mathrm{~m}^{-3}$ were observed.

Until recently, no information on the subsurface structure of filaments off Iberia has been available. In August 1998 a cruise took place to study a recurrent upwelling filament located near $42^{\circ} \mathrm{N}$. In situ measurements of the hydrographic, velocity and turbulent dissipation structure were obtained together with Lagrangian observations, both on the continental shelf near the filament origin and in the filament itself. In both experiments, direct observations of turbulence patches within the water column were made with a freefalling probe. The measurements provided insight into some of the physical processes affecting the filament at its origin and offshore; these allowed estimations to be made of the vertical mixing rates, which are of interest to the production studies, and so provide the physical context for the inter-disciplinary investigation of the exchanges across the continental margin.

\section{Data and methods}

The physical sampling strategy on board RRS 'Charles Darwin' cruise 114 was designed to support Lagrangian primary production experiments conducted on the shelf during Leg 1 (2-10 August 1998; Fig. 1) and in the filament during Leg 2 (11-20 August; Fig. 2). Further physical observations were made following the drift experiments, at a time series station on the shelf and in a spatial survey of the filament structure. In the shelf experiment the measurements were focussed around a drifting primary production 


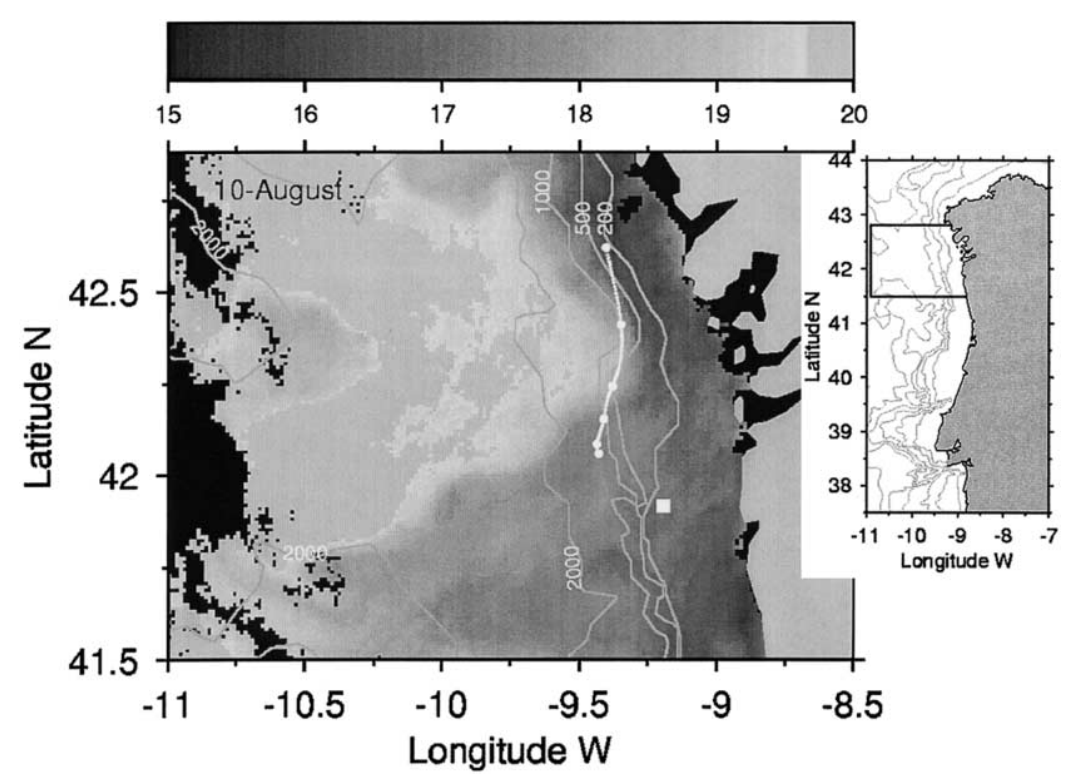

Fig. 1. Drifter track and the position of the time series observations of Leg 1 (2-10 August 1988) overlaid on the sea surface temperature image of 10 August. Colder upwelled waters are seen along the coast and extending offshore in the filament south of $42^{\circ} \mathrm{N}$. The drifter was always inshore of the upwelling front, which receded towards the coast during the observations. Isobaths are shown in metres.

rig, whereas during the filament, the primary production rig and a recoverable Argos buoy were deployed at the centre of a cluster of four other Argos drifters. Details of the rigs and their track characteristics are detailed in Joint et al. (2001).

The positions for the deployment of the drifters for the filament experiment on 14 August (Fig. 2(b)) were chosen on the basis of SST images transmitted to the ship during previous days. Horizon Marine drifters were released at the corners of a $5 \mathrm{~nm}$ side square centred on the core of the upwelling filament. They were equipped with cylindrical 'holey sock' drogues $(8 \mathrm{~m}$ length, $1.5 \mathrm{~m}$ of diameter) set at a nominal depth of $15 \mathrm{~m}$. They were tracked with the ARGOS system, which yielded 6-8 fixes per day.

Conductivity-temperature-depth probe (CTD) casts were made, approximately every $6 \mathrm{~h}$, during both legs of the cruise adjacent to the primary production rig. Additional casts were made across the base of the $42^{\circ} \mathrm{N}$ filament and on other short sections. A total of 83 casts were made during the cruise. CTD data were calibrated against in situ water samples and reversing digital thermometers.

Velocity profiles along the ship track were obtained with a RD Instruments hull-mounted $153.6 \mathrm{kHz}$ narrow-band ADCP. The Acoustic Doppler Current Profiler data set and details of processing are given in Torres and Barton (1999). The bin size was set at $8 \mathrm{~m}$ and data from above $25 \mathrm{~m}$ were rejected as being unreliable. ADCP data were recorded in 5 min ensembles during Phase 1, and in 2 min ensembles during Phase 2. The overall quality of Leg 1 data was good, with a typical depth range of $300 \mathrm{~m}$ or to the sea bed on the continental shelf. Leg 2 data, recorded in $5 \mathrm{~min}$ ensemble averages, were of poorer quality with penetration typically to only $150 \mathrm{~m}$ because sea states were rougher and there were fewer appropriately sized scatterers in the water column.

Direct observations of dissipation were made with the Free-falling Light Yo-yo (FLY) shear microstructure profiler (Dewey et al., 1987). During the six day Lagrangian productivity drifter experiment on the shelf (Leg 1, Phase 1), groups of dissipation profiles were made approximately every $6 \mathrm{~h}$. Each group, or series, contained about 10 profiles. Leg 1, Phase 2 comprised an Eulerian internal wave experiment lasting 


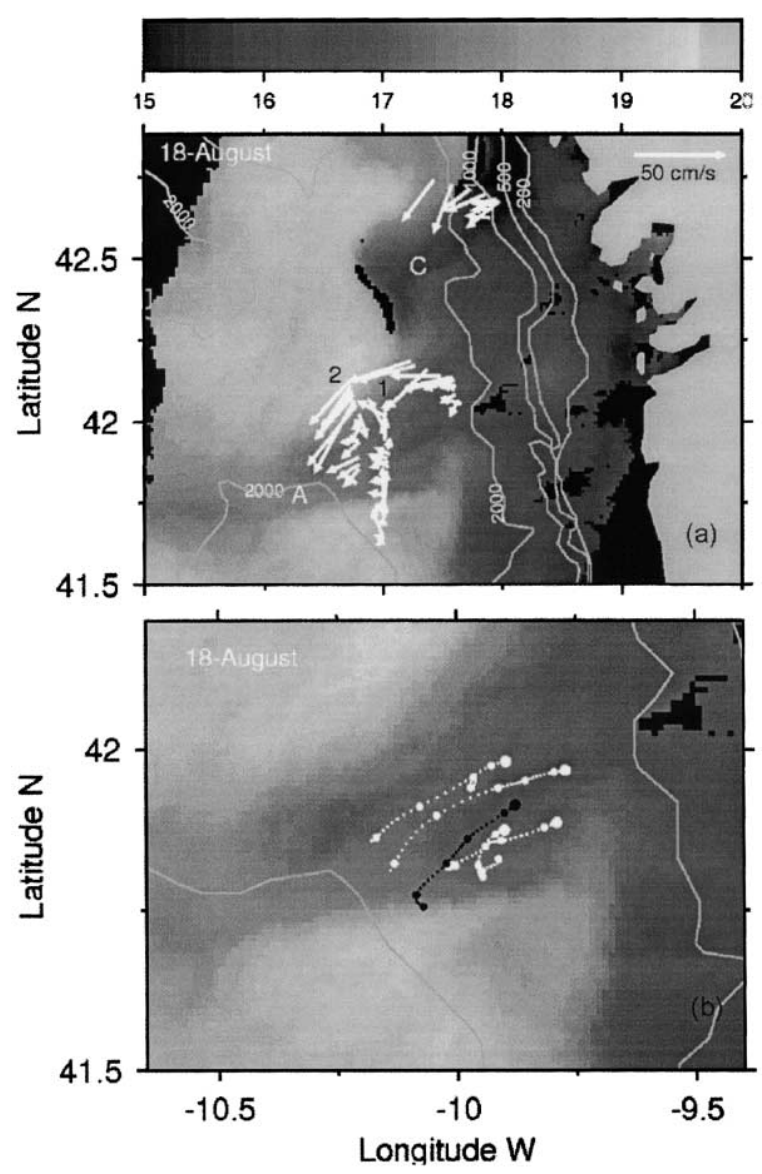

Fig. 2. (a) Absolute ADCP velocities at $25 \mathrm{~m}$ along sections during Leg 2 (12-22 August 1988) overlaid on the sea surface temperature image of 18 August. Colder upwelled waters extend from the coast beyond the shelf break and offshore in filament A south of $42^{\circ} \mathrm{N}$. A newly developing filament C is seen near $42.5^{\circ} \mathrm{N}$. Isobaths are shown in metres. (b) Drifter tracks from 14 to 19 August superimposed on enlargement of SST image of (a). Large dots mark the release point and smaller dots start of each day. The instrument rig track is shown in black. The isobath shown is $2000 \mathrm{~m}$.

about $24 \mathrm{~h}$ at a location $5 \mathrm{~km}$ inshore of the shelf break where the sounding was about $170 \mathrm{~m}$ (Fig. 1). FLY profiled the water column with a repeat cycle of $\sim 6$ min with breaks of 20 to 30 min every 3 to 4 $\mathrm{h}$ for battery recharging. At the same time a light-weight mooring was deployed with temperature miniloggers spaced vertically every $5 \mathrm{~m}$ and an $\mathrm{S} 4$ current meter near the surface at $10 \mathrm{~m}$; both miniloggers and the current meter recorded data every $30 \mathrm{~s}$.

During Leg 2, the filament was sampled with the FLY probe, CTD and shipborne ADCP. As the drifter array moved away from the coast, partial across-filament transects were observed. These were interspersed every $6 \mathrm{~h}$ with biology stations conducted next to the primary production buoy. The detailed spatial sampling of the filament was undertaken with the FLY in $\sim 10$ min cycles of 3-5 profiles to an average depth of $250 \mathrm{~m}$. Calculation of the rate of turbulent kinetic energy (TKE) dissipation from the FLY shear microstructure data followed Dewey et al. (1987) and Inall (1998). FLY temperature and conductivity records were calibrated against the calibrated CTD data. 


\section{Results}

\subsection{Background and evolution}

The seasonal cycle in the wind is clear in the interannual mean of derived Ekman transport (Smyth, Miller, Groom, \& Lavender, 2001). In 1998, wind became upwelling favourable in April, earlier than in an average year, and was stronger than average until it reached a peak in August. Wind strength dropped quickly in September to weaker than average values, but remained weakly upwelling favourable until December.

In AVHRR images a band of cold upwelled water was clearly visible next to the coast after 12 June 1998. The upwelling front quickly developed short scale instabilities like the ones described by Haynes et al. (1993). The sustained northerly winds drove the upwelling front steadily offshore until the area of upwelled water expanded across the $200 \mathrm{~m}$ isobath late in June; it was at this time that the first filamentlike structure developed off Cape Finisterre. By 4 July, two filaments, one at $42^{\circ} \mathrm{N}$ and one at Cape Finisterre were fully developed. The $42^{\circ} \mathrm{N}$ filament (Filament A after Smyth et al., 2001) remained detectable until the end of the upwelling season (late September) whereas the Finisterre filament disappeared in mid-July when the band of upwelled water receded in the north and became wider south of $42^{\circ} \mathrm{N}$.

During the cruise, winds were generally upwelling favourable in direction but underwent several cycles of relaxation and strengthening (Fig. 3). On 31 July, prior to Leg 1, winds were blowing strongly ( $\sim 15 \mathrm{~m}$ $\mathrm{s}^{-1}$ ) towards the southwest. During 2-5 August the wind backed to blow more southwards and weakened $\left(5-10 \mathrm{~m} \mathrm{~s}^{-1}\right)$. Then towards the end of the shelf drift experiment it died away almost completely when the internal wave observations were made on 8-9 August. There were strong southerly winds during the
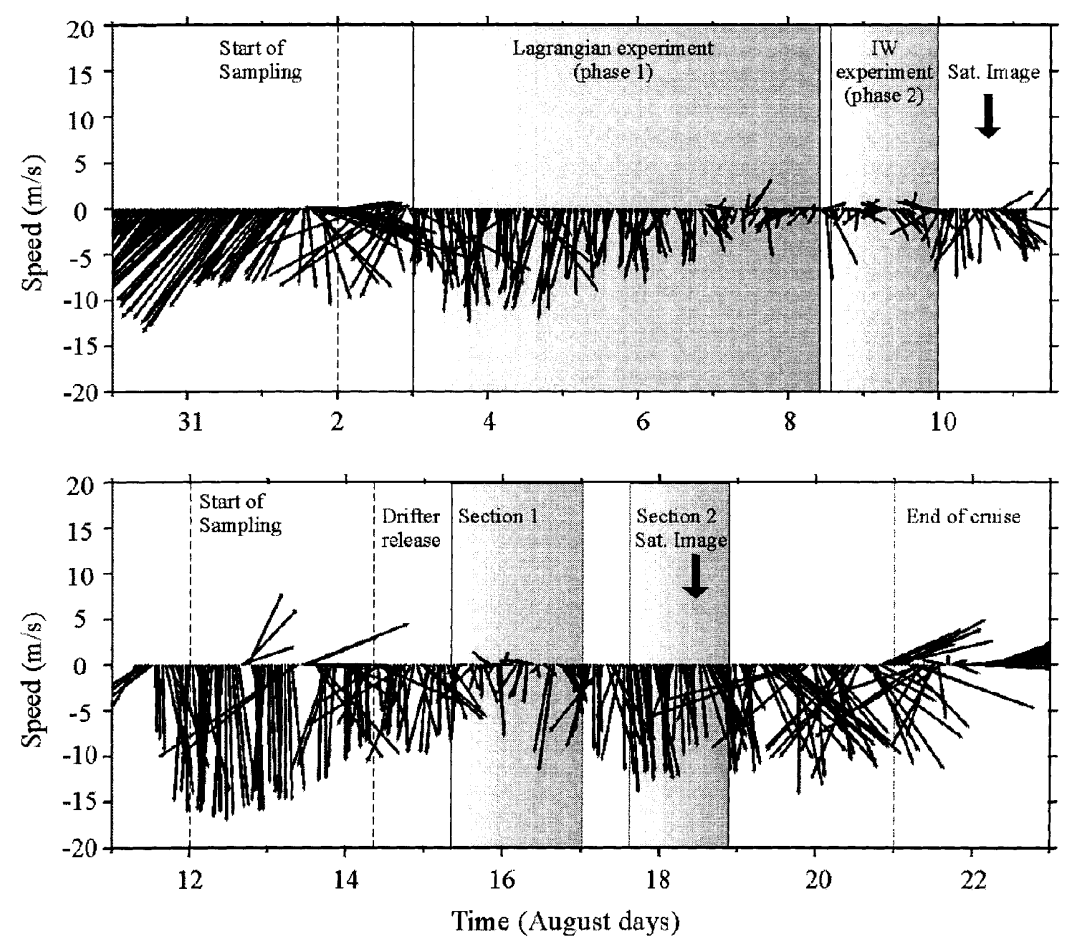

Fig. 3. Wind vector series for Leg 1 (upper) and Leg 2 (lower). Southward wind vectors point vertically down the page. Timing of the different experiments is shown. 
first days of the Leg 2 filament experiment, but again they weakened from $10 \mathrm{~m} \mathrm{~s}^{-1}$ on 13 August to become calm on 16 August, when the first filament section was completed. Winds strengthened again to $\sim 10 \mathrm{~m} \mathrm{~s}^{-1}$, when the second filament section was observed on 17-18 August and blew steadily until the end of the cruise.

Filament $\mathrm{A}$ at $42^{\circ} \mathrm{N}$ was present throughout, although it waxed and waned in response to the winds fluctuations between being more and less upwelling. At the start of the cruise in early August the other filament (B) was evident at $41.5^{\circ} \mathrm{N}$. The sequence of SST images shown in Smyth et al. (2001) shows how this filament moved north and merged with filament A by 10 August, at the end of the first period of wind relaxation. As strong winds were re-established on 12 August, the band of coastal upwelling widened and the definition of the filament A in the SST images strengthened. The subsequent period of wind relaxation was evident in later images as a narrowing and weakening of filament $\mathrm{A}$. At the time of the spatial sampling, it was $30 \mathrm{~km}$ wide and over $200 \mathrm{~km}$ long.

\subsection{The shelf experiment Leg 1}

\subsubsection{Water column structure and fluxes during the drift}

As the wind relaxed during the Phase 1 drift experiment, the internal water column structure remained essentially unchanged, suggesting that the buoy had remained within a single near-surface water packet (fig. 2 of Joint et al., 2001). The drifter moved out over deeper waters during the last two days of the experiment, and the daily mean surface temperature increased by $\sim 1.5^{\circ} \mathrm{C}$ as the surface layers stratified in near zero wind (Fig. 4). This rise in SST occurred throughout the region (Smyth et al., 2001). Shipborne ADCP records made within $1.5 \mathrm{~km}$ of the rig during its drift show there was a change from the initially relatively strong $\left(>0.3 \mathrm{~m} \mathrm{~s}^{-1}\right)$ southward flow, to a weaker $\left(<0.1 \mathrm{~m} \mathrm{~s}^{-1}\right)$ northward flow (Fig. 4). The east-west component of flow was predominantly shorewards flow during the first days of the series, even though winds were still strongly upwelling favourable and would be expected to correspond to offshore flow.

This apparent paradox of a net onshore flow component during the period of upwelling favourable winds can be resolved by considering the volume fluxes in relation to the orientation of the bathymetry (Fig. 5). Both the buoy trajectory and pseudo-trajectories calculated from the ADCP data at different levels (all low-pass filtered with a half power point at $40 \mathrm{~h}$ ), show the overall flow was broadly following the pattern of the isobaths. Average depth-integrated eastward and northward fluxes were calculated daily from the ADCP data and extended to the surface with the drifter velocities. When superimposed on the midday positions along the buoy's track, the weakening and reversal of the alongshore flux vectors with time is evident. On 3 August although the flux had a significant eastward component, relative to the local isobaths it was directed offshore, consistent with the shelf regime locally feeding water into the filament at $42^{\circ} \mathrm{N}$. The flux components, rotated along and across the local isobath direction, and estimated over each day's drift (Fig. 5 inset), show the weakening and reversal to poleward of the along-isobath flow. At the same time there was a decrease of cross-isobath flux toward deeper water and subsequent reversal to shoreward, i.e. a cut off of water supply to the filament. The exceptional shoreward flux on 4 August was associated with an abrupt change in the poorly defined bathymetry and could well be caused by an inappropriate selection of the 'along-isobath' direction for that day.

The drift experiment was followed by a 2-day time series station (Phase 2) at a site where the depth was $140 \mathrm{~m}$ and the local bathymetry was oriented almost exactly north-south. Wind was minimal at the start of the station and the small net fluxes over the two days there were shoreward and poleward (Fig. 6), indicative of a relaxation. Variability was dominated by the internal tides. However, during the series, the southerly component of the wind increased sufficiently to produce a mean equator-wards flow in the near-surface water overlying a deeper pole-ward flow, and weak offshore flow at the shallowest levels 
(a)

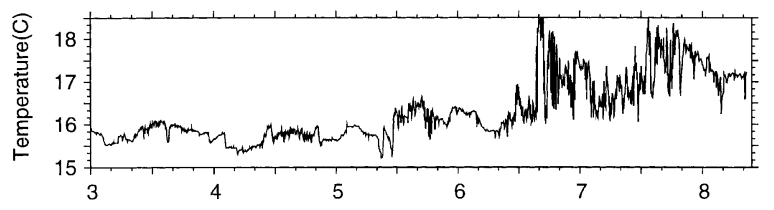

(b)

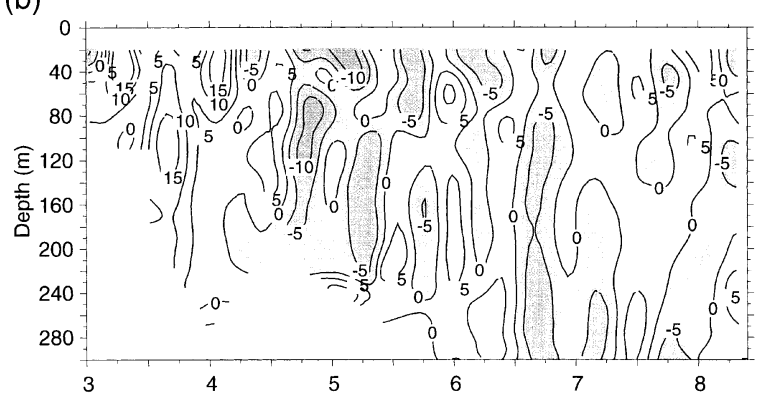

(c)

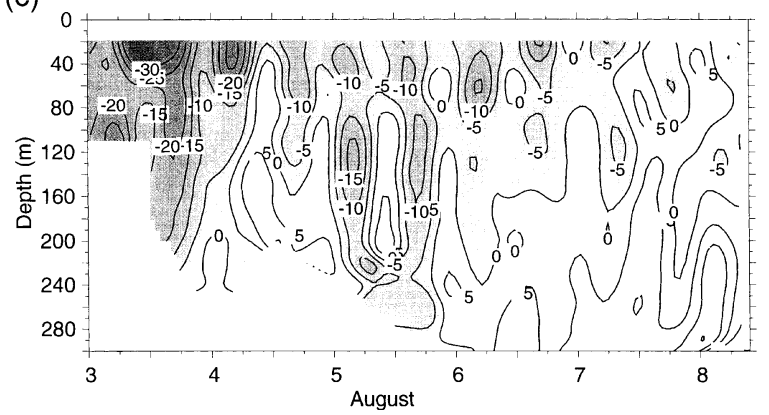

Fig. 4. Surface temperature (a), east-west (b) and north-south (c) components of shipborne ADCP velocity during the shelf drift experiment. The buoy gradually moved into deeper water.

sampled by the ADCP. A slight decreasing trend in surface temperature was consistent with a renewal of weak upwelling.

\subsubsection{The barotropic and internal tide}

During Leg 1 the tidal range at Vigo varied from $1.35 \mathrm{~m}$ (neaps, $31 \mathrm{July}$ ) to $3.55 \mathrm{~m}$ (springs, 9 August). Phase 1 thus took place while the tidal range was increasing but the intensity of upwelling was weakening. In the early part of the experiment the drifter was located in shallow water on the shelf and the northward component of the ADCP current data indicates the existence of a mode 1 internal tide with a top to bottom maximum vertical shear of about $0.15 \mathrm{~m} \mathrm{~s}^{-1}$ (Fig. 4). Later on the drifter moved out over the slope and not only was the observed tidal shear much reduced, but it also had a complicated vertical structure (as expected for a shelf edge). Near the end of the experiment the phase lag of the eastward component increased towards the surface, indicating that the tidal energy was moving upward and that part of the internal tide observed on the shelf during Phase 2 may have originated offshore.

Spring tide currents from 8-10 August (which includes the Phase 2 Eulerian experiment) are shown in Fig. 6. The semidiurnal barotropic current had an amplitude of about $0.04 \mathrm{~m} \mathrm{~s}^{-1}$, which was smaller than the amplitude of the shear in the internal tide (about $0.10 \mathrm{~m} \mathrm{~s}^{-1}$ between the upper and lower layers). The internal tide also displaced the thermocline vertically by about $12 \mathrm{~m}$ at $60 \mathrm{~m}$ depth (Fig. 7). Superimposed 


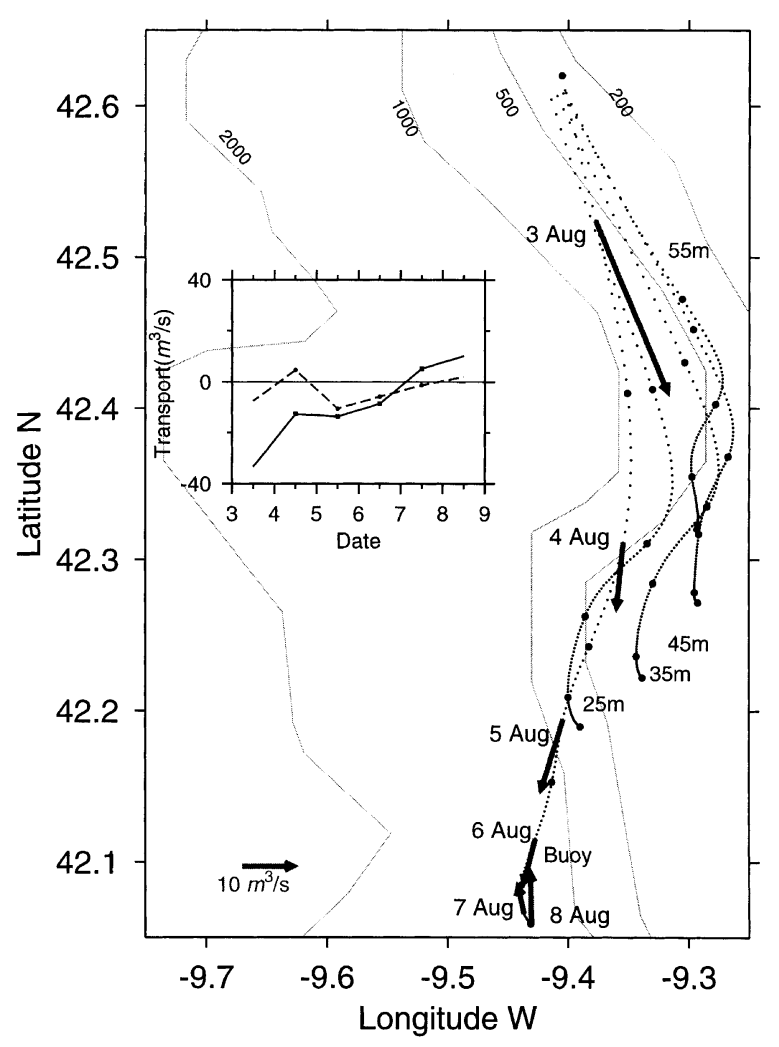

Fig. 5. Smoothed track of the drift buoy and pseudo-trajectories calculated from shipborne ADCP observations during the shelf experiment, showing the flow following the isobaths (indicated in $\mathrm{m}$ ). The dots mark each day beginning on 3 August. The arrows indicate the direction and strength of the integrated daily transport. Shown inset are the daily transport components across (dashed) and along (solid line) local isobaths. Note the change from offshore southward transport to onshore poleward.

on this semi-diurnal wave were high frequency waves with amplitudes of up to $10 \mathrm{~m}$ and periods of about $0.5 \mathrm{~h}$. High frequency internal waves observed elsewhere (including those at $41^{\circ} \mathrm{N}$ ) generally cluster in a small group at a particular phase of the tide, for example in the trough of the internal tide. They are often ' $\mathrm{KdV}$ ' type non-linear waves, which depress the thermocline but do not raise it. By contrast the high frequency waves observed in Phase 2 were distributed uniformly through the tidal cycle and appeared to have a sinusoidal form about the local mean level of the thermocline (Fig. 7).

A Synthetic Aperture Radar (SAR) image taken a few days earlier on 4 August at 2249 UTC (Fig. 8) shows the surface signature of some high frequency internal waves propagating towards the coast. This direction is close to the orientation of the maximum variance in the high-pass ( $2 \mathrm{~h}$ ) filtered S4 current meter record.

\subsubsection{Dissipation and mixing rates}

It is possible to compare mixing in the thermocline at the shelf edge (Phase 1) and on the shelf (Phase 2) from the Leg A dissipation measurements. The values have been derived by integrating TKE dissipation $(\varepsilon)$ and vertical eddy diffusivity $\left(K_{Z}\right)$ between the $16.2^{\circ} \mathrm{C}$ and $13.5^{\circ} \mathrm{C}$ isotherms, and taking the average of those integrals over time. The upper limit was chosen to avoid integrating the dissipation measurements above the surface mixed layer depth (MLD). In addition, the mean dissipation in the bottom boundary 
(a)

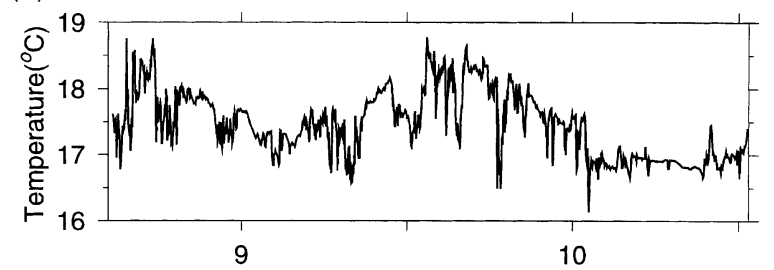

(b)
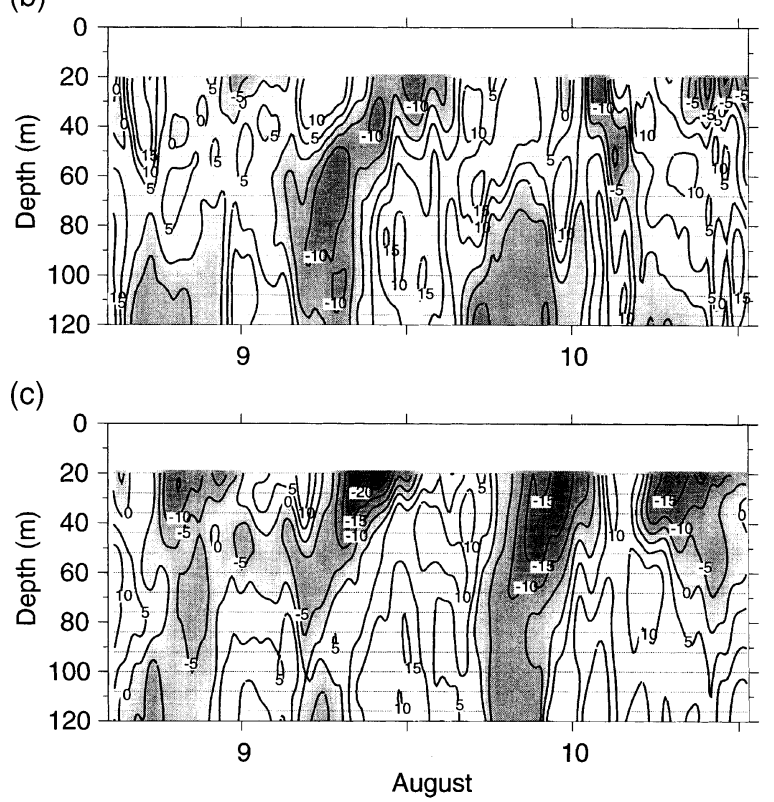

Fig. 6. Surface temperature (a), east-west (b) and north-south (c) components of shipborne ADCP velocity during the shelf time series experiment.

layer (BBL) up to $10 \mathrm{~m}$ above the sea-bed was calculated on the shelf. It was not considered meaningful to repeat this calculation at the shelf edge because of the wide variation in the depth of the profiles.

Dissipation rates in the thermocline over the shelf edge were about double those on the shelf (Table 1), where enhanced rates tended to coincide with increased fine scale shear $(S$, computed between $8 \mathrm{~m}$ ADCP bins) associated with internal waves (Figs. 7(b) and (c)). There were insufficient observations at the shelf edge to explain the higher overall dissipation there. On the shelf dissipation in the BBL was about five times greater than in the thermocline.

The lowest mixed layer temperature $\left(16.3^{\circ} \mathrm{C}\right)$ was during 4 to 5 August, when the layer was at its deepest $(\sim 35 \mathrm{~m})$. During Phase 2 the MLD remained shallower than $10 \mathrm{~m}$, and had a temperature of $16.8-18^{\circ} \mathrm{C}$. The vertical diffusion coefficient was also higher at the shelf edge $\left(1.0 \mathrm{~cm}^{2} \mathrm{~s}^{-1}\right)$ than on the shelf $(0.5$ $\mathrm{cm}^{2} \mathrm{~s}^{-1}$ ) and about three orders of magnitude greater than molecular viscosity.

Confidence in the success of the experimental strategy in estimating dissipation rates, and hence vertical mixing, was assessed using a non-parametric (bootstrap) method (e.g. Press, Teulosky, Vetterling, \& Flannery, 1992). This gave a $95 \%$ probability that the value of $K_{Z}$ lay between $0.4 \mathrm{~cm}^{2} \mathrm{~s}^{-1}$ and $1.6 \mathrm{~cm}^{2} \mathrm{~s}^{-1}$ during Phase 1 , and between $0.3 \mathrm{~cm}^{2} \mathrm{~s}^{-1}$ and $0.7 \mathrm{~cm}^{2} \mathrm{~s}^{-1}$ during Phase 2. The wider range during Phase 1 is probably a result of the more intermittent sampling, and the longer duration of the time series. To put 

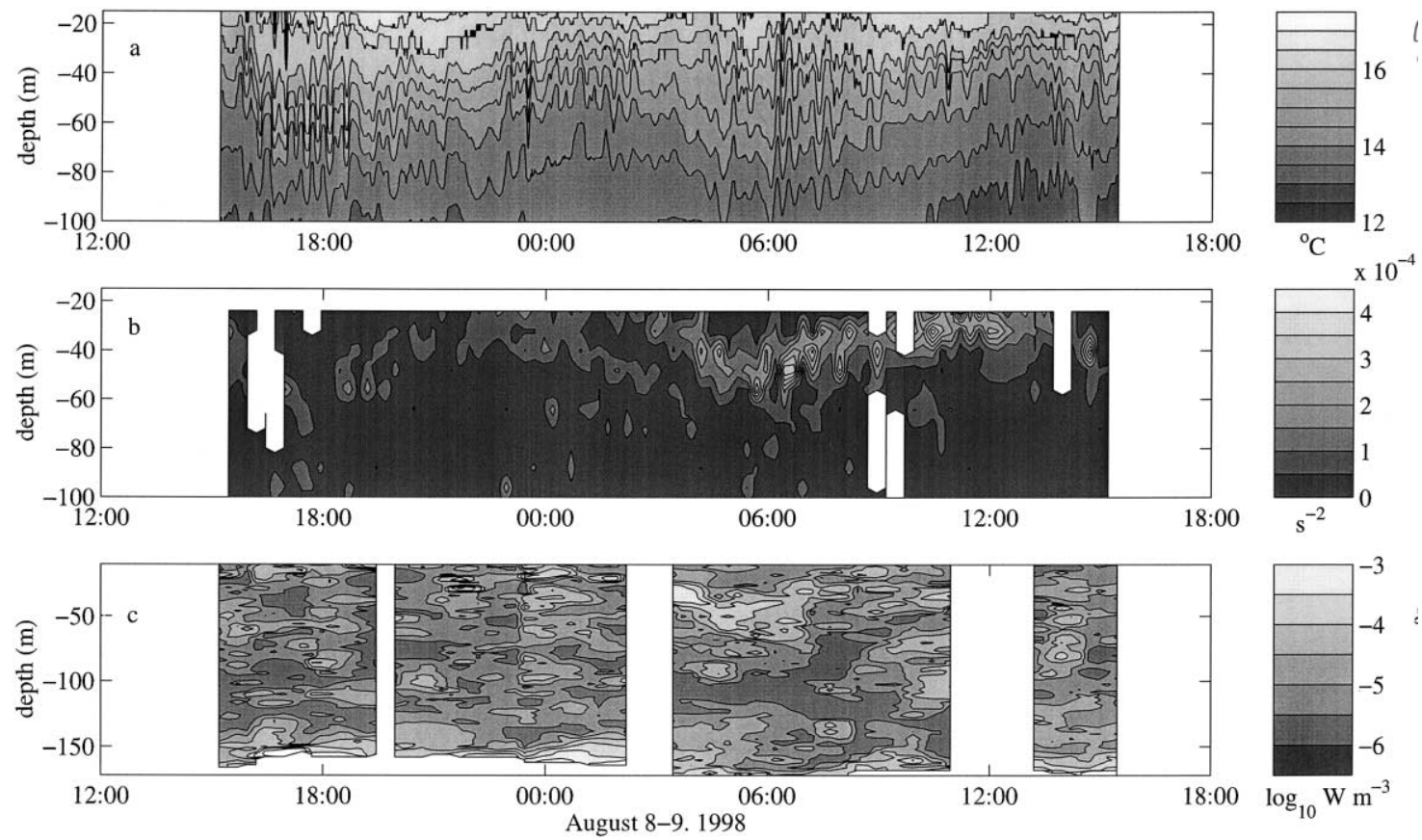

Fig. 7. (a) Contour plots of temperature from moored miniloggers. (b) Shear squared from hull mounted ADCP, interpolated onto the same grid as $\varepsilon$. (c) $\varepsilon$, the dissipation rate from FLY profiler.

the Galician Shelf in context, the mean values are similar to those observed on the Scotian Shelf, but at least an order of magnitude smaller than those estimated at $41^{\circ} \mathrm{N}$ and observed on the Malin Shelf.

\subsection{The filament experiment Leg 2}

\subsubsection{The drifters and water column structure}

Mixed-layer drifters were deployed near the southern core of the filament (Fig. 2(b)) during the weakening of the winds on 14 August. As the wind continued to decrease in strength from 10 to $3 \mathrm{~m} \mathrm{~s}^{-1}$ during the next 2 days, the drifters moved slowly offshore $\left(0.05 \mathrm{~m} \mathrm{~s}^{-1}\right)$ and converged towards the filament's southern boundary. The convergence rate, calculated following Brink et al. (1991), was consistent with a localised sinking at the southern boundary of about $10 \mathrm{~m} \mathrm{~d}^{-1}$. The wind intensified again to $10 \mathrm{~m} \mathrm{~s}^{-1}$ on 17-18 August and the two northern drifters accelerated before the others. One of the northern drifters traced the offshore extent of the filament's northern boundary with a mean velocity of $0.28 \mathrm{~m} \mathrm{~s}^{-1}$. The others, which had by then crossed the southern boundary, re-circulated shoreward with an average velocity of $0.17 \mathrm{~m} \mathrm{~s}^{-1}$ in an apparent return flow. It took them a further 20 days to complete the circuit of the gyre and to return close to the launch site.

The MLD in the centre of the buoy array was initially $25 \mathrm{~m}$ and decreasing (Fig. 9), but as the array drifted towards the southern boundary it deepened to near $50 \mathrm{~m}$. The boundary was marked by the decrease in the salinity maxima at 50-100 $\mathrm{m}$, a weak surface minimum of temperature and density, and the maximum MLD. 


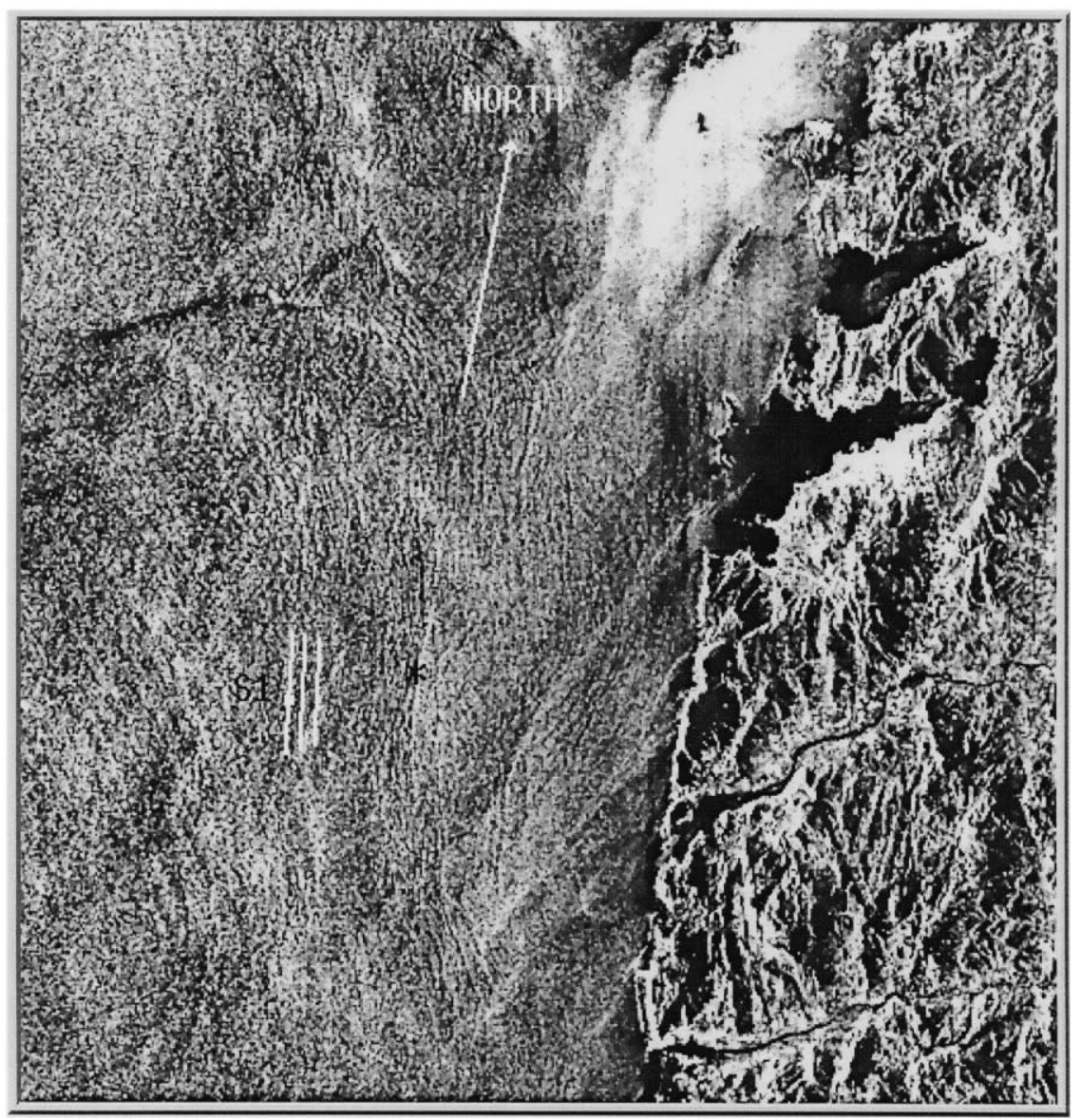

Fig. 8. SAR image showing internal wave phase lines. Direction of propagation estimated from the moored current meter and true north are marked. Image courtesy of P. Miller, Plymouth Marine Laboratory.

Table 1

Vertical eddy diffusivity and vertically integrated dissipation rates for Phases 1 and 2

\begin{tabular}{|c|c|c|c|c|c|}
\hline & $\begin{array}{l}K_{Z} \\
\left(\mathrm{~cm}^{2} \mathrm{~s}^{-1}\right)\end{array}$ & $\begin{array}{l}\text { 95\% confidence limits } \\
\left(\mathrm{cm}^{2} \mathrm{~s}^{-1}\right)\end{array}$ & $\begin{array}{l}\text { Thermocline dissipation } \\
\left(\mathrm{W} \mathrm{m}^{-2}\right)\end{array}$ & $\begin{array}{l}\text { BBL dissipation } \\
\left(\mathrm{W} \mathrm{m}^{-2}\right)\end{array}$ & 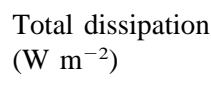 \\
\hline Phase 1 & 1.0 & 0.6 & $2.4 \times 10^{-3}$ & & $6.5 \times 10^{-3}$ \\
\hline Phase 2 & 0.5 & 0.2 & $1.5 \times 10^{-3}$ & $8.3 \times 10^{-3}$ & $9.8 \times 10^{-3}$ \\
\hline
\end{tabular}

\subsubsection{Filament cross sections}

A complete FLY crossing of the filament was undertaken while the wind speed was increasing on 1718 August (section 2 in Fig. 2(a)). The surface signal of both frontal boundaries was clearly seen in temperature, salinity and density (Figs. 10(a)-(c)). Both temperature and salinity were lowest in the filament core $\left(<17.5^{\circ} \mathrm{C},<35.55\right.$, respectively) and increased away from the core by up to $2^{\circ} \mathrm{C}$ and 0.2 at sharp $(<4 \mathrm{~km})$ frontal boundaries. The associated temperature and density gradients were very similar in both fronts, less than $0.7^{\circ} \mathrm{C} \mathrm{km}^{-1}$ and $0.06 \mathrm{~kg} \mathrm{~m}^{-3} \mathrm{~km}^{-1}$. 

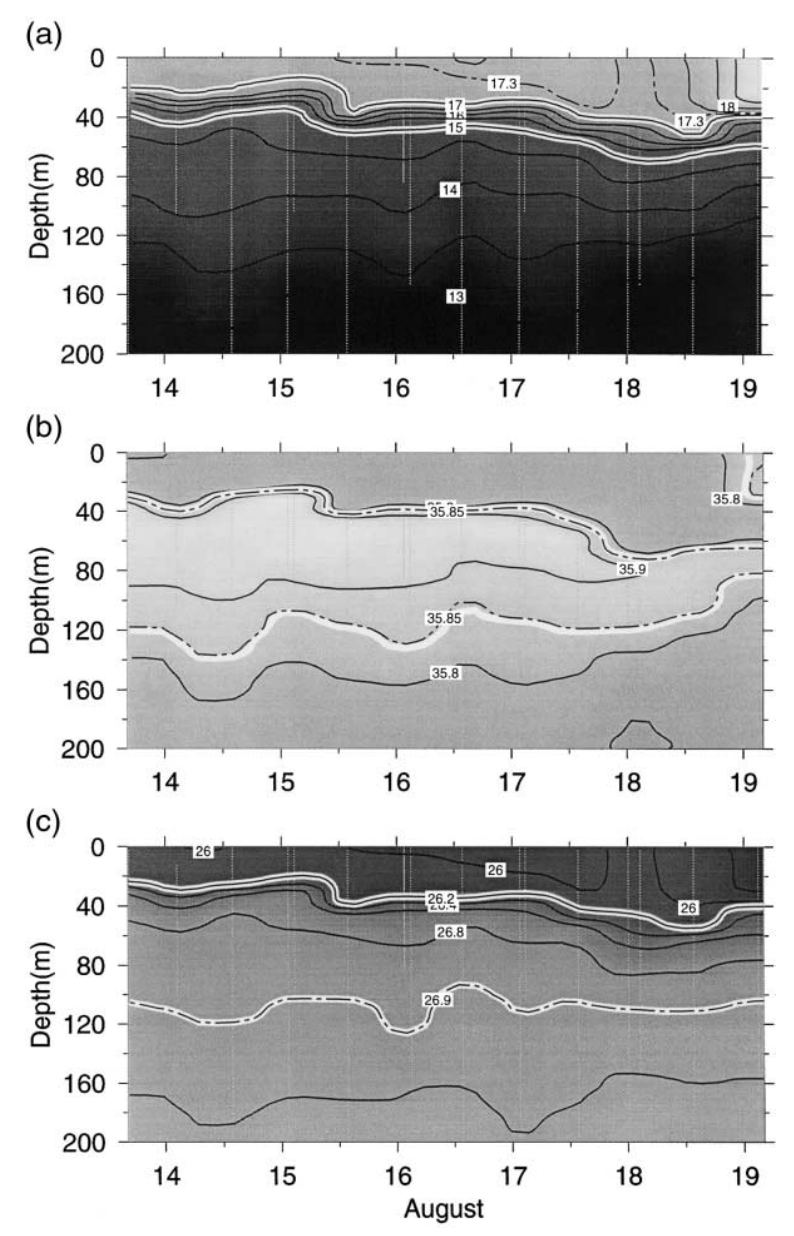

Fig. 9. Temperature (a), salinity (b) and density (c) from the CTD time series following the filament drifting productivity buoy.

The filament presented a double core structure resulting from its merger during Leg 1 with the filament 2, which had originated at $41.5^{\circ} \mathrm{N}$ (see Smyth et al., 2001). The temperature, salinity and density fields in Figs. 10(d)-(f)d-f show the double core structure as two separate domes evident down to $200 \mathrm{~m}$. The section was not continued far enough to sample the full extent of the frontal regions but they seemed to be restricted to the top $60 \mathrm{~m}$. The pycnocline was situated around $40 \mathrm{~m}$, deepening at the fronts, particularly the northern one, in relation to the stronger baroclinicity seen there in the velocity data. At the core of the filament, water below $50 \mathrm{~m}$ was characterised by a salinity maximum $(>35.9 \%)$ that did not extend across the fronts.

Figs. 10(h) and (i)h and i show the velocity structure through the filament rotated into along and across filament components. The first available ADCP bin $(25 \mathrm{~m})$ showed intensification of offshore flow at the filament boundaries, with larger values at the northern boundary $\left(>0.35 \mathrm{~m} \mathrm{~s}^{-1}\right)$ than at the southern one $\left(\sim 0.1 \mathrm{~m} \mathrm{~s}^{-1}\right)$. The horizontal shear associated with the fronts was also higher in the north, $0.5 f$ compared to $0.15 f$ for the southern boundary $\left(f \sim 9.7 \times 10^{-5} \mathrm{~s}^{-1}\right)$. Flow within the filament itself was generally very weak and, remarkably, directed offshore only in the upper $50 \mathrm{~m}$; below that the flow was weakly $(0.05-$ $0.1 \mathrm{~m} \mathrm{~s}^{-1}$ ) onshore. Near the fronts, the flow was offshore down to the maximum penetration of the ADCP with a surface intensified jet showing stronger baroclinity in the north than in the south. The total offshore 
(a)

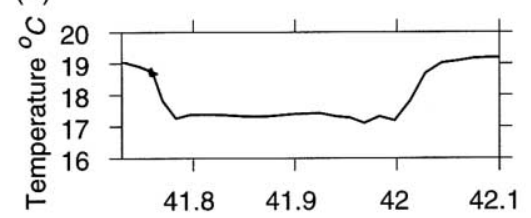

(d)

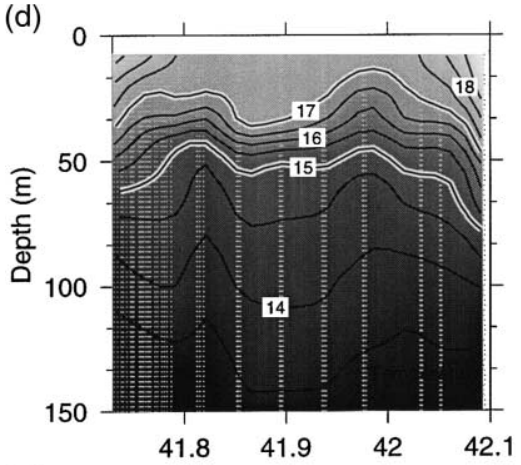

(g)

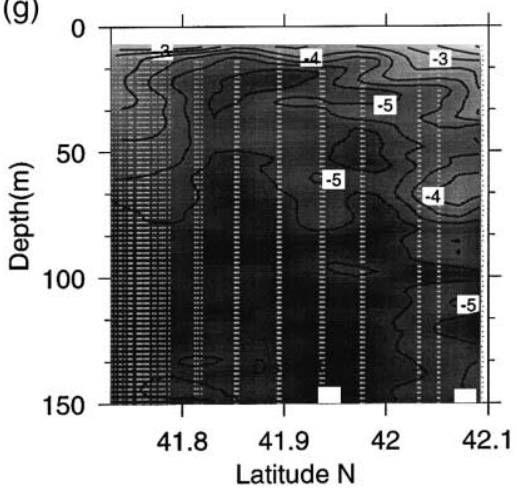

(b)

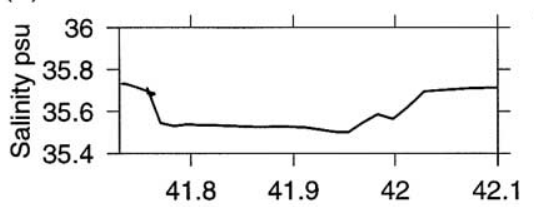

(e)

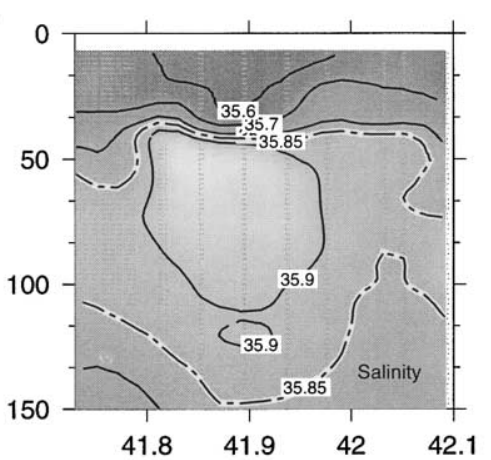

(h)

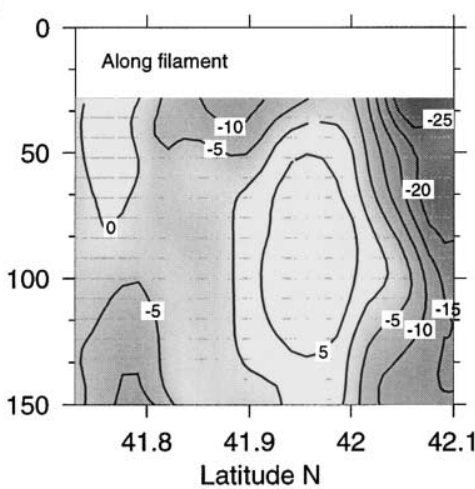

(c)

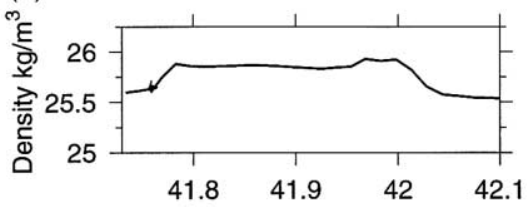

(f)

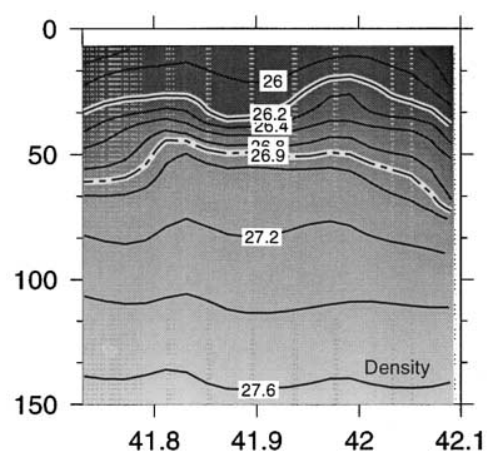

(i)

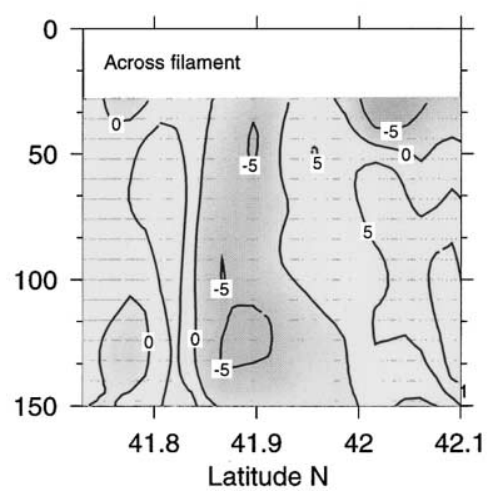

Fig. 10. Sea surface profiles along section 2 of Fig. 2(a) of (a) temperature (b) salinity and (c) density. Distributions of (d) temperature, (e) salinity, (f) density and (g) log dissipation rate on section 2. Distributions of along (h) and across filament (i) velocity on section 2. Note onshore flow beneath the centre of the filament and weak convergence to its southern side. The CTD casts during the filament drift experiment shown in Fig. 9 were made from 41.94 to $41.76^{\circ} \mathrm{N}$.

volume transport calculated in the section was only $0.5 \mathrm{~Sv}$, which is less than reported for filaments in other regions, though offshore flow extended beyond the northern limit of the section and may be underestimated slightly.

\subsubsection{Water masses}

The AVHRR image (Fig. 2) gives no indication of whether filament A was a superficial or a substantive oceanographic feature. However, a TS diagram of selected CTD casts during the cruise (Fig. 11) provides evidence that it was surprisingly shallow, and that the only part that included water that had been upwelled on the shelf was in the surface layers. These layers had a salinity of $\sim 35.74$, indicating they had originated at a depth of about $180 \mathrm{~m}$. Their temperature was $1-1.5^{\circ} \mathrm{C}$ less than that of surrounding oceanic surface waters, suggesting that there had been considerable warming of the upwelled water as it advected offshore. The mid-depth filament waters (yellow in Fig. 11), on the other hand, had a signature that was closer to the surrounding sub-surface oceanic water (red) than the upwelled shelf water (orange). This interpretation 


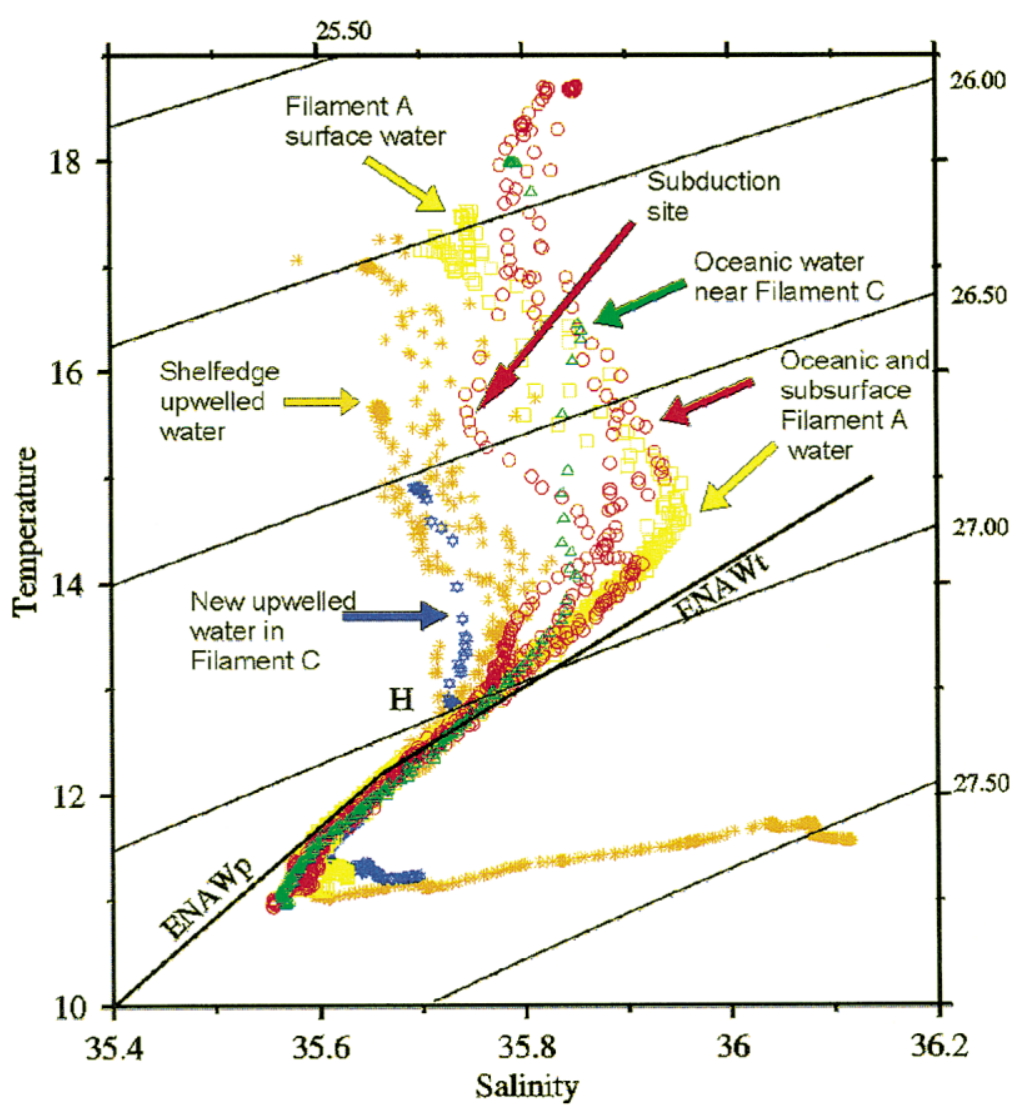

Fig. 11. TS plot of selected CTD stations showing the different water masses in filaments A and C. See text for details.

is consistent with the observed along-filament flow (Fig. 10) where oceanic water was carried shoreward beneath a superficial offshore moving filament structure. A single CTD profile made on the filament's southern boundary (red, and marked 'Subduction site') had TS characteristics that lay between those of the upwelled water and the truly oceanic stations. At and just beneath the surface its properties were oceanic, but below $20 \mathrm{~m}$ there was a salinity minimum which had the same value as that of the upwelled water in the surface layer of the filament. This suggests there had been some subduction in the convergence zone, as was indicated by the drifter tracks (Fig. 2). In another actively growing filament C, which started to develop close to Finisterre after 13 August (described in more detail by Smyth et al., 2001) conditions contrasted with those of the weakening filament $\mathrm{A}$. Throughout its depth range filament $\mathrm{C}$ was composed of colder, newly upwelled water (blue) moving offshore.

\subsubsection{Turbulence observations}

Enhanced mixing was observed in both fronts (Fig. 10(g)) although larger integrated values were found on the northern boundary. In the filament core, active mixing was restricted to the surface $15 \mathrm{~m}$, while in the fronts, high values of TKE penetrated to $80 \mathrm{~m}$ in the northern boundary and $60 \mathrm{~m}$ in the southern boundary. Representative values of integrated TKE and derived $K_{Z}$ for the thermocline are presented in Table 2 . The thermocline was subjectively chosen to be $15-17^{\circ} \mathrm{C}$, and total dissipation was integrated over the depth of the dissipation profiles (typically $250 \mathrm{~m}$ ). $K_{Z}$ estimates spanned three orders of magnitude across the filament. Estimated errors were similar to those for the shelf experiment, albeit with less confi- 
Table 2

Vertical eddy diffusivity and vertically integrated dissipation rates for the filament survey

\begin{tabular}{lllll}
\hline & $\begin{array}{l}K_{Z} \\
\left(\mathrm{~cm}^{2} \mathrm{~s}^{-1}\right)\end{array}$ & $\begin{array}{l}75 \% \text { confidence limits } \\
\left(\mathrm{cm}^{2} \mathrm{~s}^{-1}\right)\end{array}$ & $\begin{array}{l}\text { Thermocline dissipation } \\
\left.(\mathrm{W} \mathrm{m})^{-2}\right)\end{array}$ & $\begin{array}{l}\text { Total dissipation } \\
\left(\mathrm{W} \mathrm{m} \mathrm{m}^{-2}\right)\end{array}$ \\
\hline South Front & 1.6 & 1.1 & $4 \times 10^{-3}$ & $8.5 \times 10^{-3}$ \\
Core & 0.02 & 0.01 & $0.3 \times 10^{-3}$ & $1.4 \times 10^{-3}$ \\
North Front & 0.1 & 0.04 & $1.5 \times 10^{-3}$ & $12.6 \times 10^{-3}$ \\
\hline
\end{tabular}

dence since they are based on fewer observations (typically 10 profiles). The enhanced localised mixing in the thermocline of the southern boundary is believed to be related to the subduction processes.

\section{Discussion}

Both periods of sampling took place when winds were changing from strongly upwelling favourable to near zero, but winds were never actually favoured downwelling. The experiments are representative of the relaxation periods following an upwelling event. In this respect, results seem typical in the indications of convergence at the filament boundary, as also observed by Flament et al. (1985) off California, the establishment of poleward flow on the shelf and slope, as off California (Winant, Beardsley, \& Davis, 1987), and the general decrease in extent of the filaments with weakening wind, previously noted off Iberia by Haynes et al. (1993). The decreasing contribution to the filament seen during the shelf experiment and the relatively small offshore filament transport-compared to 1-3 Sv in active filaments off California (Strub, Kosro, \& Huyer, 1991) and NW Africa (Barton et al., 1998)—reflect the weakening system. However, both drift experiments sampled packets of water recently upwelled and represent conditions commonly found in the highly variable system off Galicia.

The internal tide is much bigger than would be expected from local shelf edge forcing. Model predictions suggest that at $41^{\circ} \mathrm{N}$, off Portugal, a depth integrated tidal current of $10 \mathrm{~m}^{2} \mathrm{~s}^{-1}$ would generate a wave with amplitude of about $1.2 \mathrm{~m}$ and a shear of $0.04 \mathrm{~m} \mathrm{~s}^{-1}$ (Jeans, 1998). At the Galician shelf edge the equivalent current is $\sim 7 \mathrm{~m}^{2} \mathrm{~s}^{-1}$, and whilst the observed internal tide is not as big as at $41^{\circ} \mathrm{N}$, it is still an order of magnitude larger than expected. Much of the Iberian shelf edge thus appears to have a larger than expected internal tide. The apparently ubiquitous presence of the large $0.5 \mathrm{~h}$ period sinusoidal internal waves is a surprise-it is more usual to observe packets of high frequency waves of depression at a shelf edge. SAR images (e.g. Fig. 8) suggest that the internal wave regime off Galicia is more chaotic than that observed at $41^{\circ} \mathrm{N}$, or in other parts of the world. It is possible that internal tide generation is complicated by a response involving the Galicia Bank and three-dimensional features along the shelf edge. Since the dissipation measurements at the fixed station were conducted during spring tides the observed values probably represent an upper bound for this part of the shelf. However, this cannot be certain given the rather unusual nature of the internal wave regime.

There was enhanced mixing in the thermocline at the shelf edge, which was directly linked to the shear created by the internal tide combined with the high frequency internal waves. The observed diffusion levels (order $1 \mathrm{~cm}^{2} \mathrm{~s}^{-1}$ ) are at the lower end of the range of values observed at the shelf edge, comparable to the Scotian Shelf (Sandstrom \& Oakey, 1995), but considerably less than on the Malin Shelf (Inall et al., 2000) or at $41^{\circ} \mathrm{N}$ (Jeans, personal communication). There was considerable spatial variability in the observations of diffusion in the filament. On its southern boundary the levels were similar to those observed at the shelf edge (about $1.6 \mathrm{~cm}^{2} \mathrm{~s}^{-1}$ ), whilst on its northern boundary they were an order of magnitude smaller. Very low values were observed within the core of the filament (about $0.01 \mathrm{~cm}^{2} \mathrm{~s}^{-1}$ ). This distribution of 
vertical mixing is closer to that observed in the wide eddy like structure off Oregon (Moum et al., 1988), than the narrow filament off California (Dewey, Moum, \& Caldwell, 1993). It is not possible to give a specific explanation for these differences from the observations made in the filament, but it is clear that the enhanced diffusion coefficients occurred in regions of high shear.

A vertical mixing time, $\tau$, across a thermocline of thickness $h$, should approximate to $\tau=h^{2} / K_{Z}$, on dimensional grounds. If $h$ is (say) $20 \mathrm{~m}$ then $\tau$ will increase from about 1 month to 1 year as $K_{Z}$ decreases from 1 to $0.1 \mathrm{~cm}^{2} \mathrm{~s}^{-1}$. On the shelf a rate of $1 \mathrm{~cm}^{2} \mathrm{~s}^{-1}$ would be large enough to cause the thermocline both to broaden and to transport material into the lower layers over the duration of summer. However, in the lifetime of a filament (order 1 week) vertical mixing makes only a small contribution to the evolution of the temperature and nutrient structure. Any observed changes must result from other horizontally dominated factors, such as eddies. At the southern boundary convergence appears to dominate vertical mixing, causing the boundary to sink at about $10 \mathrm{~m}^{-1 a y}{ }^{-1}\left(\tau=7\right.$ days when $h=10 \mathrm{~m}$ and $K_{Z}=1.6 \mathrm{~cm}^{2} \mathrm{~s}^{-1}$ ). Water mass characteristics within the filament will not be significantly modified by vertical mixing during its lifetime, though they will be gradually changed by surface warming and horizontal exchanges.

The apparently anomalous double core structure of filament A may result from several factors. It was one of the 'oldest' filaments, having developed at the start of the upwelling season, and had therefore been subject to several cycles of development and relaxation prior to sampling. Moreover, it had merged with a second filament (B) that had arisen some distance to the south. The shoreward flow in its centre was probably a relic of the recirculation between the originally separate filaments A and B. Finally, it was sampled during a period of minimal wind, when the slow drifter speeds and convergence indicate relaxation of the system, so that its structure may not be typical of an active filament. In this respect, filament $\mathrm{C}$ may have been more representative, but developed too late to be thoroughly sampled. The presence of shoreward flow beneath the surface signature of the merged filaments underlines the difficulty of making transport estimates based solely on remotely sensed sea surface temperatures.

Finally, the results show that there is not a simple one way transport from shelf to open ocean or subsurface to surface. Three of the four filament deployed drifters recirculated shoreward. Their trajectories suggest that at least some waters transported offshore in the filament may return to near slope within a time scale of a month. However, it must be remembered that the behaviour of surface drifters, where they crossed the convergence zone on the filament boundary, is not truly Lagrangian, since they cannot follow submerging water parcels. The evidence of subduction at the southern boundary of the filament implies vertical recirculation of water parcels on a relatively short time scale. Given the typically 10 day cycling of wind forcing observed here, these vertical exchanges may have implications on significant biological time scales.

\section{Conclusions}

A combination of Lagrangian and other observations has revealed complex features of the upwelling filament system on and offshore of the NW Iberian continental shelf. Observations were made during a period of upwelling favourable but weakening winds.

1. On the shelf near the source of the $42^{\circ} \mathrm{N}$ filament, it was found the net offshore flux to the filament decreased as upwelling favourable winds relaxed to near zero. At the same time alongshore currents reversed to slightly poleward.

2. The internal tide on the outer shelf had an amplitude of about $12 \mathrm{~m}$ in the thermocline, much larger than can be explained by local shelf edge forcing. Large quasi-sinusoidal short period internal waves combined with the internal tide to enhance vertical mixing in filament source waters near the shelf edge. Associated estimates of $K_{Z}$ lay in the range $0.5-1 \mathrm{~cm}^{2} \mathrm{~s}^{-1}$. 
3. The $42^{\circ} \mathrm{N}$ filament had an unusual double core structure as a result of an earlier merger of two separate filaments. Remnant return flow below the surface carried oceanic water shoreward between and under the two merged filament cores.

4. Offshore transport in the filament was estimated at only $0.5 \mathrm{~Sv}$ moving offshore, which was small compared to filament transports reported elsewhere. This low level of transport is compatible with measurements made during a weakening of the upwelling and almost certainly underestimates transport in a developing filament.

5. Enhanced turbulence was found in the filament boundaries, and probably results from stronger baroclinic shear at the northern boundary $\left(K_{Z}=0.1 \mathrm{~cm}^{2} \mathrm{~s}^{-1}\right)$ and possible subduction at the southern boundary $\left(K_{Z}=1.6 \mathrm{~cm}^{2} \mathrm{~s}^{-1}\right)$. Overall vertical mixing in the filament itself appeared to be small $\left(K_{Z}=0.01 \mathrm{~cm}^{2} \mathrm{~s}^{-1}\right)$.

6. Drifters showed some of the water transported off shelf in the filament was carried far out to sea, but a portion was recirculated on a time scale of a month back to the shelf edge. This has strong implications for the biology of the region and in particular the retention of larvae spawned on the shelf.

The present observations were obtained in support of a multi-disciplinary cruise with multiple objectives and because of sampling compromises are not synoptic but only representative of restricted areas at specific times. Nevertheless, the data set provides new information on the behaviour of the filament system and highlights important questions as to the initiation and decay of filament structures.

\section{Acknowledgements}

Satellite images were received by the NERC Dundee Satellite Receiving Station, and processed by Peter Miller at the NERC-CCMS Remote Sensing Group in Plymouth (www.npm.ac.uk/rsdas/). The captain and crew of RRS Charles Darwin are thanked for their help during the experiments. This work was supported by the European Union in the framework of the MAST 3 programme, contract number MAS3-CT97-0076 (OMEX project).

\section{References}

Barton, E. D., Arístegui, J., Tett, P., Cánton, M., García-Braun, J., Hernández-León, S., Nykjaer, L., Almeida, C., Almunia, J., Ballesteros, S., Basterretxea, G., Escánez, J., García-Weill, L., Hernández-Guerra, A., López-Laatzen, F., Molina, R., Montero, M. F., Navarro-Pérez, E., Rodríguez, J. M., van Lenning, K., Vélez, H., \& Wild, K. (1998). The transition zone of the Canary Current upwelling region. Progress in Oceanography, 41, 455-504.

Brink, H. H., Beardsley, R. C., Niiler, P. P., Abbott, M., Huyer, A., Ramp, S., Stanton, T., \& Stuart, D. (1991). Statistical properties of near-surface flow in the California Current Coastal Transition Zone. Journal of Geophysical Research, 96, $14693-14706$.

Brink, K. H., \& Cowles, T. J. (1991). The Coastal Transition Zone program. Journal of Geophysical Research, 96, $14637-14647$.

Craig, P. D. (1987). Solutions for internal tide generation over coastal topography. Journal of Marine Research, 45, 83-105.

Dewey, R. K., Crawford, W. R., Gargett, A. E., \& Oakey, N. S. (1987). A microstructure instrument for profiling oceanic turbulence in coastal bottom boundary layers. Journal of Atmosphere and Ocean Technology, 4, 288-297.

Dewey, R. K., Moum, J. N., \& Caldwell, D. R. (1993). Microstructure activity within a minifilament in the Coastal Transition Zone. Journal of Geophysical Research, 98, 14457-14470.

Flament, P., Armi, L., \& Washburn, L. (1985). The evolving structure of an upwelling filament. Journal of Geophysical Research, 90, 11765-11778.

Gerkema, T., \& Zimmerman, J. T. F. (1995). Generation of nonlinear tides and solitary waves. Journal of Physical Oceanography, 25, 1081-1094.

Haynes, R., Barton, E. D., \& Pilling, I. (1993). Development, persistence and variability of upwelling filaments off the Atlantic Coast of the Iberian Peninsula. Journal of Geophysical Research, 98, 22681-22692.

Inall, M. E., Rippeth, T. P., \& Sherwin, T. J. (2000). Impact of nonlinear waves on the dissipation of internal tidal energy at a shelf break. Journal of Geophysical Research, 105, 8687-8705. 
Inall, M. (1998). Software to process and image dissipated energy rates. UCES report U98-7, University of Wales Bangor, UK. Jeans, D. R. G. (1998). A nonlinear internal tide on the Portuguese shelf. PhD Thesis, University of Wales, Bangor, $152 \mathrm{pp.}$

Joint, I., Inall, M., Torres, R., Figueiras, F. G., Alvarez-Salgado, X. A., Rees, A. P., \& Woodward, E. M. S. (2001) Two Lagrangian experiments in the Iberian Upwelling System: tracking an upwelling event and an offshore filament. Progress in Oceanography, 51 (2-4), 221-248.

Moum, J. M., Caldwell, D. R., \& Stabeno, P. J. (1988). Mixing and intrusions in a rotating cold-core feature off Cape Blanco, Oregon. Journal of Physical Oceanography, 18, 823-833.

Osborn, T. R. (1980). Estimates of the local rate of vertical diffusion from dissipation measurements. Journal of Physical Oceanography, 10, 83-89.

Press, W. H., Teulosky, S. A., Vetterling, W. T., \& Flannery, B. P. (1992). Numerical recipes (2nd ed.). Cambridge University Press.

Roed, L. P., \& Shi, X. B. (1999). A numerical study of the dynamics and energetics of cool filaments, jets and eddies off the Iberian peninsula. Journal of Geophysical Research, 104, 29817-29842.

Sandstrom, H., \& Oakey, N. S. (1995). Dissipation in internal tides and solitary waves. Journal of Physical Oceanography, 25, 604-614.

Smyth, T. J., Miller, P. I. Groom, S. B., \& Lavender, S. J. (2001). Remote sensing of sea surface temperature and chlorophyll during Lagrangian experiments at the Iberian margin. Progress in Oceanography, 51 (2-4), 269-281.

Strub, P. T., Kosro, P. M., \& Huyer, A. (1991). The nature of the cold filaments in the California Current System. Journal of Geophysical Research, 96, 14743-14768.

Torres, R., \& Barton, E. D. (1999). Charles Darwin Cruise 114: Acoustic Doppler Current Profiler report. Data report, University of Wales, Bangor, UK.

Winant, C. D., Beardsley, R. C., \& Davis, R. E. (1987). Moored wind, temperature and current observations made during Coastal Ocean Dynamics Experiment 1 and 2 over the northern California continental shelf and upper slope. Journal of Geophysical Research, 92, 1569-1604. 